\title{
EDITORIAL
}

\section{Multilevel perspectives on pathways to resilient functioning}

\author{
DANTE CICCHETTI $^{a}$ AND W. JOHN CURTIS ${ }^{b}$ \\ ${ }^{a}$ University of Minnesota; and ${ }^{b}$ University of Rochester
}

Throughout the course of the 20th century, increased attention was directed toward the importance of applying a multiple levels of analysis approach to the investigation of normal and atypical developmental processes (Cicchetti \& Valentino, 2007). The movement toward a multiple levels of analysis perspective is exemplified by research conducted in the fields of contemporary neuroscience and developmental psychopathology (Cicchetti, 2002). Similar to the historical growth witnessed in neuroscience (Cowan, Harter, \& Kandel, 2000), developmental psychopathology has evolved as a field that is the product of the integration of various disciplines (Cicchetti, 1990). The influence of diverse disciplines on developmental psychopathology illustrates the manner in which advances in our knowledge of the operation of developmental processes within particular scientific domains mutually inform each other. These multidisciplinary origins helped to facil-

We are grateful to the National Institute of Drug Abuse (DA17741) and the Spunk Fund, Inc. for their support of our work on this project. This Special Issue is dedicated to Marianne Gerschel in recognition of both her longstanding support of research on the determinants of resilience and her passion and commitment to improving the lives of disenfranchised persons. Her ongoing efforts have made a major difference in the outcomes of many heretofore ignored children and families.

Address correspondence and reprint requests to: Dante Cicchetti, Institute of Child Development, University of Minnesota, 51 East River Road, Minneapolis, MN; or W. John Curtis, Mt. Hope Family Center, University of Rochester, 187 Edinburgh Street, Rochester, NY 14608. itate and forge the emphasis that developmental psychopathologists have placed on the importance of investigating the processes and pathways to maladaptation, psychopathology, and resilience (Cicchetti, 1984, 1993; Cicchetti \& Sroufe, 2000).

Despite the fact that it has become increasingly apparent that progress toward a process-level understanding of maladaptive, psychopathological, and resilient outcomes will necessitate the implementation of research designs and strategies that call for the simultaneous assessment of multiple domains of variables both within and outside the developing person, this interdisciplinary systems-level approach has yet to be brought to bear in the scientific study of resilience (Cicchetti \& Blender, 2004, 2006; Curtis \& Cicchetti, 2003; Luthar, Cicchetti, \& Becker, 2000). Empirical investigations of resilience over the past 40 years have examined a wide range of psychosocial correlates of, and contributors to, the phenomenon (Luthar, 2006; Luthar \& Brown, 2007; Masten, 2007; Masten \& Obradović, 2006). In recent years, a number of scientists have urged researchers studying the determinants of resilience to incorporate neurobiological and molecular genetic measures into their investigations of the developmental pathways to resilient functioning (Charney, 2004; Cicchetti \& Blender, 2006; Curtis \& Cicchetti, 2003). Technological advances in neuroimaging, magnetoencephalography, electroencephalographic recording, neuroendocrinology, and molecular genetics have made it more feasible to conduct 
research on the development of resilience from a multilevel perspective.

Contributors to this Special Issue, many of whom have not previously focused their research efforts on discovering the processes contributing to resilient functioning, were asked to examine their data from a multilevel perspective on resilience. Through stretching beyond their typical "comfort zones," we thought that a fresh perspective could be brought to bear that would facilitate the understanding of resilient adaptation. Indeed, this Special Issue contains a number of the first empirical studies that have investigated the processes and pathways to resilience from a multilevel perspective.

Because the authors of the contributions in this Special Issue each have examined diverse levels of analysis and their relation to resilient outcomes, these and future studies that adopt a multiple levels of analysis approach should have important implications for resiliencepromoting interventions (Luthar, 2006). Luthar and Cicchetti (2000) stated that such resiliencepromoting interventions should target protective and vulnerability forces at multiple levels of influence.

The utilization of a neurobiological framework and the incorporation of genetically sensitive designs into interventions seeking to promote resilient functioning or to repair positive adaptations gone awry may contribute to the ability to design individualized interventions

\section{References}

Charney, D. (2004). Psychobiological mechanisms of resilience and vulnerability: Implications for successful adaptation to extreme stress. American Journal of Psychiatry, 161, 195-216.

Cicchetti, D. (1984). The emergence of developmental psychopathology. Child Development, 55, 1-7.

Cicchetti, D. (1990). A historical perspective on the discipline of developmental psychopathology. In J. Rolf, A. Masten, D. Cicchetti, K. Nuechterlein, \& S. Weintraub (Eds.), Risk and protective factors in the development of psychopathology (pp. 2-28). New York: Cambridge University Press.

Cicchetti, D. (1993). Developmental psychopathology: Reactions, reflections, projections. Developmental Review, 13, 471-502.

Cicchetti, D. (2002). How a child builds a brain: Insights from normality and psychopathology. In W. Hartup \& R. Weinberg (Eds.), Minnesota Symposia on Child Psychology: Child psychology in retrospect and prospect (Vol. 32, pp. 23-71). Mahwah, NJ: Erlbaum. that are based on knowledge gleaned from multiple biological and psychological levels of analysis. If assessments of biological systems are routinely incorporated into the psychological measurement batteries employed in resilience-promoting interventions, then we will be in a position to discover whether the nervous system, as well as psychological processes, have been modified by experience.

Future research on resilience should continue to integrate biological and psychological perspectives with the goals of translating this research into the design and implementation of preventive interventions that aim to facilitate the development of resilient functioning (Cicchetti \& Toth, 2006; Curtis \& Cicchetti, 2003; Luthar, 2006). A challenge that will need to be surmounted involves the determination of the mechanisms whereby different levels of analysis interact across developmental time. Furthermore, researchers conducting their work at each level will need to develop theories that are consistent across all levels of analysis. Although investigations that focus purely on the behavioral level of resilience remain valuable and worthwhile, it is now essential that researchers who examine the determinants of resilience integrate empirical work conducted on the behavioral level with the biological and genetic levels, examine their coactions, and investigate the relations among these mutually influencing systems.

Cicchetti, D., \& Blender, J. A. (2004). A multiple-levels-ofanalysis approach to the study of developmental processes in maltreated children. Proceedings of the National Academy of Sciences USA, 101, 17325-17326.

Cicchetti, D., \& Blender, J. A. (2006). A multiple-levels-ofanalysis perspective on resilience: Implications for the developing brain, neural plasticity, and preventive interventions. Annals of the New York Academy of Sciences, 1094, 248-258.

Cicchetti, D., \& Sroufe, L. A. (2000). The past as prologue to the future: The times, they've been a changin' [Editorial]. Development and Psychopathology, 12, 255-264.

Cicchetti, D., \& Toth, S. L. (2006). Developmental psychopathology and preventive intervention. In A. Renninger \& I. Sigel (Eds.), Handbook of child psychology (6th ed., pp. 497-547). New York: Wiley.

Cicchetti, D., \& Valentino, K. (2007). Toward the application of a multiple-levels-of-analysis perspective to research in development and psychopathology. In A. Masten (Ed.), Minnesota Symposia on Child 
Psychology (Vol. 34, pp. 243-284). Mahwah, NJ: Erlbaum.

Cowan, W. M., Harter, D. H., \& Kandel, E. R. (2000). The emergence of modern neuroscience: Some implications for neurology and psychiatry. Annual Review of Neuroscience, 23, 343-391.

Curtis, W. J., \& Cicchetti, D. (2003). Moving research on resilience into the 21st century: Theoretical and methodological considerations in examining the biological contributors to resilience. Development and Psychopathology, 15, 773-810.

Luthar, S. S. (2006). Resilience in development: A synthesis of research across five decades. In D. Cicchetti \& D. J. Cohen (Eds.), Developmental psychopathology: Vol. 3. Theory and method (2nd ed., pp. 739-795). New York: Wiley.
Luthar, S. S., \& Brown, P. J. (2007). Maximizing resilience through diverse levels of inquiry: Prevailing paradigms, possibilities, and priorities for the future. Development and Psychopathology, 19, 931-955.

Luthar, S. S., \& Cicchetti, D. (2000). The construct of resilience: Implications for intervention and social policy. Development and Psychopathology, 12, 857-885.

Luthar, S. S., Cicchetti, D., \& Becker, B. (2000). The construct of resilience: A critical evaluation and guidelines for future work. Child Development, 71, 543-562.

Masten, A. S. (2007). Resilience in developing systems: Progress and promise as the fourth wave rises. Development and Psychopathology, 19, 921-930.

Masten, A. S., \& Obradović, J. (2006). Competence and resilience in development. Annals of the New York Academy of Sciences, 1094, 13-27. 